of Mountain Medicine. If the promise of the first few issues is borne out, this journal could become the standard home for interdisciplinary papers in the high-altitude life sciences.

Ronald J. White and Jancy C. McPhee are at the National Space Biomedical Research Institute and Baylor College of Medicine, One Baylor Plaza, NA-425, Houston, Texas 77030, USA.

www.liebertpub.com/ham

\section{Outlook on \\ a crisis discipline}

\section{Conservation Genetics}

editor A. R. Hoelzel

Kluwer. 4/yr. 217 euros, \$218 (institutional); 63.50 euros, $\$ 60$ (individual)

\section{Oscar E. Gaggiotti}

As the editor of Conservation Genetics notes in the journal's first issue, conservation biology is a field that requires the integration of many disciplines - including social and economic matters - in order to address an issue that concerns us all. But is it then advisable to publish a conservation journal that focuses on only one of the many disciplines covered by the field? The editor, however, puts a strong case for the journal's publication, and stresses that its primary aim is to promote the application of moleculargenetics methodologies to answer pressing questions about the conservation of biodiversity.

The journal publishes research articles, review articles, commentary, short communications and technical notes. It thereby provides a wide range of options for promoting the dissemination of knowledge and for fostering discussion. And this is essential in a field where the results of scientific research can have a direct impact on the long-term survival of species.

As the founder of the field Michael Soule rightly put it, conservation biology is a crisis discipline, where scientists have to work quickly to address urgent problems. Unfortunately, when operating in crisis mode, there may be a tendency to avoid thinking about new ways of solving the problem at hand and instead to use traditional approaches. Although this is sometimes necessary, it is not a good long-term strategy, and we need a forum for discussing and thoroughly testing new ideas and approaches.

Conservation

Genetics potentially fulfil this need, but only if it avoids becoming a repository of 'dull but worthy' papers. Purely descriptive papers providing useful information on the conservation of a species or population - for example, phylogeography, genetic structure and level of genetic variability - have been accepted by the journal but represent a small fraction of all the studies it has published so far.

Most of its papers go beyond a simple enumeration of genetic attributes and try to identify possible demographic, environmental and anthropogenic factors responsible for the observed patterns. Other studies have addressed more general and important questions, such as the validity of using neutral genetic markers - those not subject to selective forces - as a surrogate for the additive genetic variation underlying the traits that are the target of selection.

But one cannot help noticing that, despite the very long list of topics the editor suggests as appropriate material for his journal, close to $50 \%$ of the papers published deal with the genetic structure and/or phylogeography of populations. This criticism may seem unfair, as it is a trend that has been observed in the early days of other journals covering the broad field of molecular ecology. However, the field of conservation genetics must not be restricted to this narrow area, and the journal should endeavour to attract more papers dealing with other topics, such as inbreeding depression, hybridization and the impact of breeding programmes on genetic diversity.

Despite this caveat, it is clear that the journal has started well, and could eventually become the leading forum for the discussion of all aspects of population genetics in conservation science.

Oscar E. Gaggiotti is in the Metapopulation

Research Group, Department of Ecology

and Systematics, PO Box 17

(Arkadiankatu 7), FIN-00014 University of Helsinki, Finland.

$$
\text { of } \mathrm{H}
$$




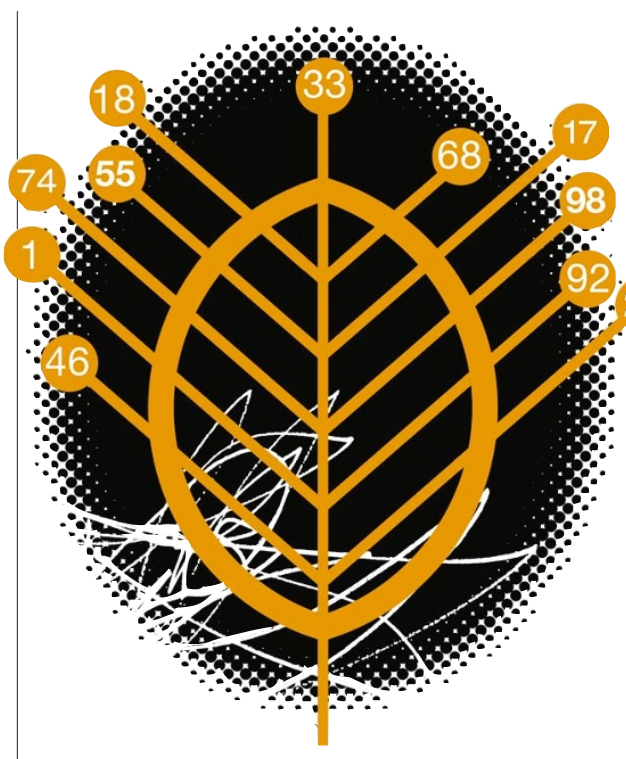

author of several Organic Letters papers, as well as a frequent reviewer, I can say from experience that the entire process is remarkably efficient and a model for the future of scientific publication. In addition, the webbased journal, as with all of the society's library, is a powerful reference source. Launched with Organic Letters was the Chemical Abstract Service (CAS) Reference Linking feature, in which virtually every reference in the electronic journal is 'hotlinked' to the corresponding CAS abstract, regardless of publisher. Moreover, references to ACS journals have a direct link to the corresponding manuscript.

The remarkably rapid turn-around time from submission to publication gives the reader the feeling of a newswire, reporting the exciting discoveries of the field almost as they occur. Organic Letters has a bright future and, from the diverse manuscripts published so far, so does the field of organic chemistry.

Richard E. Taylor is in the Department of Chemistry \& Biochemistry, University of Notre Dame, 251 Nieuwland Science Hall, Notre Dame, Indiana 46556-5670, USA.

\section{A European slant on mol biol}

\section{EMBO Reports}

senior editor Frank Gannon

Oxford University Press/European Molecular

Biology Organization. 12/yr. £320, \$522

(institutional, print \& online);

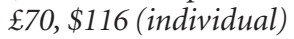

\section{Hidde Ploegh}

EMBO Reports is the second periodical to be produced jointly by Oxford University Press and the European Molecular Biology Organization. EMBO Journal, an enterprise started more than 15 years ago, is now so successful that not only is it among the highestranked molecular-biology journals, but its income also helps EMBO pay for useful things such as postdoctoral fellowships. Will its sibling, EMBO Reports, be equally successful?

The launch issue sets forth the aspirations of EMBO Reports. As far as the science is concerned: shorter articles than $E M B O$ Journal accommodates, but of the same broad scope and high quality. Here I can be brief. There is a good amount of really exciting science packed into the stream of EMBO Reports steadily arriving on my desk over the past year and a half. The editors achieved their goal by roping in the authors necessary to produce at the same level as EMBO Journal.

By far the most interesting new aspect of the journal is something not found in EMBO Journal: journalism in the form of editorials, interviews, book reviews and policy pieces. The meeting reports have substance and are far more informative than those I read in competing publications. The news editor, Holger Breithaupt, does an excellent job in several lengthy interviews with, for example, Kai Simons, Harold Varmus, Noel Treacy, Ralf Pettersson - and commentaries.

EMBO Reports cannot deal with the truly topical issues in the manner of a Science or Nature, simply because of its publication schedule, but - to name just two examples - I found the timely articles on the human genome and reproductive issues and those on the stem-cell debate thoughtful, interesting and highly readable. Thankfully, the publishers care more about substance than page limits. Also, scientists surely enjoy reading about scientific gossip and human-interest issues - the Folkman-Abbott lawsuit, some of the inner workings of the Nobel committee, concerns about degree requirements.

Of the major science publications, only a few avail themselves of the opportunity to dish out strong medicine in the opinion and policy arena, and I hope that future pieces will pack as much punch as the editorial board have so far allowed. The editorials by senior editor and EMBO executive director Frank Gannon are interesting and provocative ("Back to Darwin" is the best of the lot), although somewhat variable in octane number. An appeal for science and our role as scientists to be portrayed in a positive manner is voiced by many other publications, and I wonder what such preaching to the converted will amount to. But then, there is also a biting assessment of the fad of 'omes' and 'omics' - transcriptome, glycosylomics; even a lowly 2D-gel apparatus will henceforth be a proteomics facility. Or the question: will hypothesis-driven research be relegated to the same plane as the flat-Earthers ? This insane opinion, anonymously cited by Frank Gannon, came from a "witless 'genomics' drone somewhere in Germany" - attribution of this quote would have served more than a journalistic purpose.

I tend to think of science as a fairly global enterprise, but a 'European' odour emanates from some of the news analyses. And I wish that Europe's scientists would tell Brussels what they want and need, rather than exist in reactive mode - 'frameworks' and Eurocrats be damned. EMBO Reports could be a voice for a serious critique of Brussels' bureaucratic bungling, constructive exchanges with Euro-commissioner for research Philippe Busquin notwithstanding. Even if it is funded with money from member states of the European Commission, a watchdog function for $E M B O$ Reports might be on the cards, hopefully without fear of budgetary retribution.

The journal is a pleasure to leaf through: glossy paper, generally outstanding reproductions of photographs, high-quality graphics, all in a sober, almost conservative, design. A journal can no longer distinguish itself by showing on its covers the usual immunofluorescent and crystallographic images or their abstractions. Why not steal an idea from EMBO Journal and on occasion have real cover art? Spice up the typographic design, and commission (European) designers and artists to lend their voice to our science.

Along similar lines, a likeable feature is the inclusion of photos of the authors of reviews, interviews, meeting reports and the like. This raises the question: why not have pictures of all the women and men behind the work? EMBO Reports is a winner: if it continues to publish excellent science and grows editorial/opinion fangs of appropriate size, it will enliven debate and render an exceptional service to molecular biology. It is wonderful to see a new 